\title{
Currency Unions
}

\section{Citation}

Alesina, Alberto, and Robert J. Barro. 2002. Currency unions. Quarterly Journal of Economics 117(2): 409-436.

\section{Published Version}

http://dx.doi.org/10.1162/003355302753650283

\section{Permanent link}

http://nrs.harvard.edu/urn-3:HUL.InstRepos:4551795

\section{Terms of Use}

This article was downloaded from Harvard University's DASH repository, and is made available under the terms and conditions applicable to Other Posted Material, as set forth at http:// nrs.harvard.edu/urn-3:HUL.InstRepos:dash.current.terms-of-use\#LAA

\section{Share Your Story}

The Harvard community has made this article openly available.

Please share how this access benefits you. Submit a story.

Accessibility 


\title{
CURRENCY UNIONS*
}

\author{
Alberto Alesina and Robert J. Barro
}

Common currencies affect trading costs and, thereby, the amounts of trade, output, and consumption. From the perspective of monetary policy, the adoption of another country's currency trades off the benefits of commitment to price stability (if a committed anchor is selected) against the loss of an independent stabilization policy. We show that the type of country that has more to gain from giving up its own currency is a small open economy heavily trading with one particular large partner, with a history of high inflation and with a business cycle highly correlated with that of the potential "anchor." We also characterize the features of the optimal number of currency unions.

\section{INTRODUCTION}

In 1947 there were 76 countries in the world; today there are 193. The growth of the number of countries has led to a large increase in the number of currencies in circulation; unless one believes that a country is, by definition, an "optimal currency area," either there were too few currencies in 1947, or there are too many today. In fact, the increasing integration of international markets implies that the optimal number of currencies would tend to decrease, rather than more than double as it has.

Recently, as a result of this proliferation of currencies and a renewed emphasis on price stability, the sanctity of "one country one money" has come into question. Twelve countries in Europe have adopted the same currency, dollarization is under active consideration in many countries in Latin America and has recently been implemented in Ecuador and announced in El Salvador. Countries in Eastern Europe and the former Soviet Union are considering unilaterally adopting the euro. In addition, several countries have adopted currency boards, including Hong Kong, Argentina, and Lithuania with the dollar and Estonia and Bulgaria first with the German mark and later with the euro.

* We thank for useful suggestions Giuseppe Bertola, Edward Glaeser, Jean Imbs, Robert Hall, Lawrence Katz, Richard Portes, Helene Rey, Kenneth Rogoff, Enrico Spolaore, and participants in seminars at the European Central Bank, Harvard University, and New York University and in conferences at the Hoover Institution and Universitat Pompeu Fabra. Silvana Tenreyro provided excellent research assistance. National Science Foundation support through the National Bureau of Economic Research is gratefully acknowledged.

@ 2002 by the President and Fellows of Harvard College and the Massachusetts Institute of Technology.

The Quarterly Journal of Economics, May 2002 
These recent cases of currency adoption add to the many currency unions that have existed for some time. ${ }^{1}$

Mundell's [1961] pioneering analysis stressed two opposing forces as determinants of optimal currency areas. The benefit of a common currency was that it facilitated trade in goods and services and in financial exchanges. Money, like language, was more useful the greater the scope of its usage. The main disadvantage of a currency was that it precluded the use of independent monetary policies by the member countries or regions. Hence, monetary policy could not be tailored to an economy's individual disturbances. Mundell stressed factor mobility and price flexibility as key elements in the trade-off between the two forces.

Our analysis builds on Mundell's framework in several ways. ${ }^{2}$ First, we allow for a linkage between currency union and the volume of trade and, thereby, assess how trading costs affect the desirability of currency union. Second, we consider that currency union can commit a country to monetary stability and that this feature is especially attractive to countries that lack internal discipline. Third, we show that the potential benefit from an independent monetary policy depends on two types of comovements across countries: one involving relative outputs and the other involving relative prices. Finally, we use the framework to discuss the relation between the number and sizes of countries and the number of currencies in circulation.

We begin by characterizing the advantages of a currency union in reducing the transaction costs of trade. Recent results by Rose [2000], Frankel and Rose [2002], and Glick and Rose [2001] suggest that these benefits may be substantial, well beyond the effects from fixed exchange rates; Tenreyro [2002], however, finds smaller effects. ${ }^{3}$ We then link our analysis of trade to a monetary model that emphasizes the distinction between rules and discretion, as in Barro and Gordon [1983]. We show that the adoption of the currency of a

1. See Rose [2000] and Glick and Rose [2001] for lists of economies that use currencies other than their own. Two examples of currency unions are the French Franc Zone in Africa and the Eastern Caribbean Currency Union. Some other countries that use another nation's currency are Bermuda, Panama, Liechtenstein, Luxembourg, and San Marino.

2. Bayoumi [1994] provides a formalization of Mundell's analysis in a multiregion, general equilibrium model.

3. Several papers have investigated the effects of exchange rate stability on trade flows, reaching mixed results. See Hooper and Kohlhagen [1978], Kenen and Rodrik [1986], and International Monetary Fund [1984]. 
low-inflation anchor country "buys" credibility. ${ }^{4}$ In fact, currency adoption may work better that a fixed-rate arrangement, because it is more costly to reintroduce one's own money than to change exchange-rate parities. Hence, currency adoption is more credible. In this respect, currency boards are somewhere in between a fixed-rate arrangement and a currency union. The cost of currency adoption is the loss of monetary independence. The "client" country, which uses an anchor's currency, loses its ability to target monetary policy to domestic shocks. We examine two cases: one in which the anchor follows the same policy without regard to the interest of its clients and a second in which the clients may compensate the anchor for policy modifications.

After discussing the pros and cons of adopting another country's currency, we study how, given a distribution of independent countries, certain types of currency unions would emerge in equilibrium. We show that an increase in the number of countries (thus, a reduction in their average size) would increase the desirability of currency unions. Hence, as the number of countries increases, the number of currencies should increase less than proportionately. In fact, under certain conditions, if one moves from, say, 100 countries to 200 , the total number of currencies circulating may decrease in absolute terms. Consequently, in a world of small and highly integrated countries, where the benefits of low and stable inflation are highly valued, one should observe a collapse of the one-country, one-money identity and a move toward a world with relatively few currencies.

The paper is organized as follows. Section II presents a model that highlights the pros and cons that a country faces when considering the adoption of a foreign currency. Section III discusses several extensions of the basic model. Section IV studies the endogenous formation of currency unions given a distribution of sizes of independent countries. The last section concludes.

\section{A Model of CuRRency Unions}

\section{A. Output, Trade, and Country Size}

We begin with a simple model of the real economy with a role for trade and country size. For a more detailed development of

4. Several papers have discussed the trade-off between commitment and flexibility in the context of fixed versus flexible exchange rates, especially in the context of the European Monetary Union. See, for example, Giavazzi and Giovannini [1989] and Alesina and Grilli [1992]. 
this model, see Alesina, Spolaore, and Wacziarg [2000] and Barro and Tenreyro [2000].

Competitive firms produce output using a varieties-type production function, proposed by Spence [1976], Dixit and Stiglitz [1977], and Ethier [1982]. The output of firm $i$ is given by

$$
Y_{i}=A L_{i}^{1-\alpha} \cdot \sum_{j=1}^{N} X_{j i}^{\alpha},
$$

where $A>0$ is a productivity parameter, $L_{i}$ is firm i's employment of labor, $0<\alpha<1, X_{j i}$ is the amount of intermediate input of type $j$ used by firm $i$, and $N$ is the number of types of intermediates available (all of which will turn out to be used). Final output is a homogeneous good that can be used for consumption or to produce intermediate goods. There is only one type of consumer good.

Suppose that there are two countries, where country $I$ produces the intermediates $j=1, \ldots, N^{I}$ and country $I I$ the intermediates $j=N^{I}+1, \ldots, N$, where $N=N^{I}+N^{I I}$. Generalization to more than two countries is straightforward. We assume that the countries do not overlap in the types of intermediate goods that they produce. Hence, domestic and foreign producers do not compete directly in the provision of a particular type of intermediate input.

We think of the intermediate inputs as specialized goods, such as machine tools and computers. In practice, these goods tend to be durables, so that increases in the $X_{j i}$ require investment outlays. However, to keep things simple, we assume that the intermediate goods are nondurable. This assumption eliminates any dynamic elements, but the model can be extended, without changing the basic results, to treat the inputs as capital goods.

Within each country there is free trade and no transaction costs for shipping goods. The shipping of an intermediate good across country borders entails transaction costs, which can reflect transport expenses and trade barriers. ${ }^{5}$ Specifically, we assume an iceberg technology, whereby, for each unit of intermediate

5. A large empirical literature has shown that political borders matter greatly for the volume of trade. See, for example, McCallum [1995], Helliwell [1998], and Anderson and van Wincoop [2000]. More generally, the "home-bias" effect is pervasive in various aspects of international economic relationships, as emphasized by Obstfeld and Rogoff [2000]. 
good shipped from country $I$ to country $I I$ or the reverse, $1-b$ units arrive, with $0<b<1$. Note that the trading cost $b$ is assumed to reflect the using up of real resources, not a transfer from one party to another (as would be true for a tariff). Transaction costs for shipping final product-and, therefore, the single type of consumer good-abroad are nil. Hence, the price of final product is the same in both countries, and we normalize this price at unity.

Homogeneous labor is exchanged within each country on a competitive, countrywide market. The total quantities of labor are fixed at $L^{I}$ and $L^{I I}$, respectively. To simplify matters, we assume that a country that is larger in terms of numbers of products is larger in the same proportion in terms of labor. That is, $N^{I} / L^{I}=N^{I I} / L^{I I}$, and we normalize each of these ratios to be one.

Each firm maximizes profit, taking as given the country's wage rate and the price, $P_{j}$, of each type of intermediate good. The prices are measured in units of final product and are assumed to apply uniformly at the point of origin to all purchasers, whether domestic or foreign. The first-order conditions for the choices of intermediate inputs by the producers of final product in country $I$ are

$$
\begin{array}{ll}
A \alpha L_{i}^{1-\alpha} X_{j i}^{\alpha-1}=P_{j}, & j=1, \ldots, N^{I}, \\
A \alpha L_{i}^{1-\alpha} X_{j i}^{\alpha-1}=P_{j} /(1-b), & j=N^{I}+1, \ldots, N .
\end{array}
$$

In one setup, each type of intermediate good $j$ is provided by a single monopolistic firm. Since the marginal and average cost of production is unity, the constant-elasticity demand function implied by equation (2) leads to $P_{j}=1 / \alpha>1$. With other forms of imperfect competition, the markup price of intermediates would be some value $P_{j}=\mu_{j}$, where $1 \leq \mu_{j} \leq 1 / \alpha$. If we assume that $\mu_{j}=\mu^{I}$ in country $I\left(j=1, \ldots, N^{I}\right)$ and $\mu_{j}=\mu^{I I}$ in country $I I$ $\left(j=N^{I}, \ldots, N\right)$, then substitution of $P_{j}=\mu_{j}$ into equation (2) determines the quantities of intermediates employed by firm $i$ in country $I$ to be

$$
\begin{array}{ll}
X_{j i}=\left(A \alpha / \mu^{I}\right)^{1 /(1-\alpha)} \cdot L_{i}, & j=1, \ldots, N^{I}, \\
X_{j i}=\left[\left(A \alpha / \mu^{I I}\right) \cdot(1-b)\right]^{1 /(1-\alpha)} \cdot L_{i}, & j=N^{I}+1, \ldots, N .
\end{array}
$$

Substitution of the results from equation (3) into equation (1) and aggregation over the firms determines the level of aggregate output in country $I$ : 
(4) $Y^{I}=A^{1 /(1-\alpha)} \alpha^{\alpha /(1-\alpha)} N^{I} \cdot\left\{\left(\frac{1}{\mu^{I}}\right)^{\alpha /(1-\alpha)} \cdot N^{I}+\left(\frac{1-b}{\mu^{I I}}\right)^{\alpha /(1-\alpha)} \cdot N^{I I}\right\}$.

Higher markup ratios, $\mu^{I}$ and $\mu^{I I}$, reduce the demands for intermediates and thereby reduce output. Trading costs $b$ reinforce the foreign country's markup ratio $\mu^{I I}$ in reducing demand for imported intermediates. If $\mu^{I}=\mu^{I I}$, then $b>0$ implies that the $N^{I I}$ foreign types of intermediate goods enter with a lower weight than the $N^{I}$ domestic types.

The second part of equation (3) determines the quantity of intermediate goods produced in country $I I$ and used by finalgoods producers in country $I$. The value of these imported goods, gross of shipping costs, is determined by multiplying the quantity of intermediates by $\mu^{I I} /(1-b)$. The resulting expression for imports, which is gross of the iceberg losses on the intermediate goods shipped from country $I I$ to country $I$, is

Value of imports of intermediates to country $I$

$$
=(A \alpha)^{1 /(1-\alpha)} \cdot\left(\frac{1-b}{\mu^{I I}}\right)^{\alpha /(1-\alpha)} N^{I} N^{I I} .
$$

An expression analogous to the second part of equation (3) determines the quantity of country $I$ 's intermediates used by final-goods producers in country $I I$. The corresponding value of the exports of intermediate goods from country $I$ to country $I I$ can be calculated, after multiplication by $\mu^{I} /(1-b)$, as

(6) Value of exports of intermediates from country $I$

$$
=(A \alpha)^{1 /(1-\alpha)} \cdot\left(\frac{1-b}{\mu^{I}}\right)^{\alpha /(1-\alpha)} N^{I} N^{I I} .
$$

This expression is gross of the iceberg losses on the intermediate goods shipped from country $I$ to country $I I$.

Equations (5) and (6) imply that balanced trade in intermediate goods results if $\mu^{I}=\mu^{I I}$. Otherwise, any net surplus or deficit in the trade of intermediate goods is matched by an equalsize net deficit or surplus in the trade of final products. (We are assuming here that there are no internationally traded financial assets.)

The expressions for imports and exports of intermediate goods in equations (5) and (6) resemble gravity-type equations, in the sense of depending on the product of country sizes, $N^{I} N^{I I}$. The 
results also resemble gravity models in predicting that higher trading costs $b$ reduce the volume of trade. Empirically, the parameter $b$ relates to distance, other measures of transport costs, the nature of monetary systems, and the extent of similarities in language, legal systems, culture, colonial heritage, and other variables. We return to these issues in Section IV.

The only firms in country $I$ that make profits in equilibrium are the monopolistic providers of the intermediate goods numbered $j=1, \ldots, N^{I}$. The ownership rights in these firms are assumed to be distributed evenly across the households of country $I$. In this case, country $I$ has a representative household, whose net income and consumption correspond to gross output less the production of intermediates plus the country's net surplus in intermediate trade with country $I I{ }^{6}$ The resulting formula for consumption per person is

$$
\begin{aligned}
\frac{C^{I}}{N^{I}}=A^{1 /(1-\alpha)} \alpha^{\alpha /(1-\alpha)} \cdot\left\{( \frac { 1 } { \mu ^ { I } } ) ^ { 1 / ( 1 - \alpha ) } \cdot \left[\left(\mu^{I}-\alpha\right) \cdot N^{I}+\alpha \cdot\left(\mu^{I}-1\right)\right.\right. \\
\left.\left.\quad \times(1-b)^{\alpha /(1-\alpha)} \cdot N^{I I}\right]+(1-\alpha) \cdot\left(\frac{1-b}{\mu^{I I}}\right)^{\alpha /(1-\alpha)} \cdot N^{I I}\right\} .
\end{aligned}
$$

If $\mu^{I}=\mu^{I I}=\mu$, this formula simplifies to

(8) $\frac{C^{I}}{N^{I}}=A^{1 /(1-\alpha)} \alpha^{\alpha /(1-\alpha)} \cdot(\mu-\alpha) \cdot\left(\frac{1}{\mu}\right)^{1 /(1-\alpha)}$

$$
\times\left[N^{I}+(1-b)^{\alpha /(1-\alpha)} \cdot N^{I I}\right] .
$$

The following qualitative implications of the model are intuitively reasonable and generalize beyond the specific setting that we have adopted.

- If trading costs $b$ were zero and pricing were competitive (which corresponds to $\mu^{I}=\mu^{I I}=1$ ), then $Y^{I}$ and $C^{I}$ would be proportional to the world's number of intermediates, $N=N^{I}+N^{I I}$. In this case, the relative size of the country, measured by $N^{I} / N$, would not matter. More generally, for given $N^{I}$, a higher $N$ raises $Y^{I}$ and $C^{I}$.

- If trading costs exist, then $Y^{I}$ and $C^{I}$ increase with $N^{I}$ for

6. This equality holds because there is, by assumption, no net borrowing or lending between the two countries. Otherwise, some disturbances-such as a temporary shock to the markup ratio in one country-might motivate net borrowing or lending. The introduction of these international capital flows would not change any of the main results. 
given $N$. This effect arises because an increase in the size of the country expands the number of intermediate inputs for which the trading costs are nil.

- $Y^{I}$ and $C^{I}$ are decreasing in the trading cost parameter $b$.

- For given $N$, the larger the country, $N^{I}$ (and, hence, the smaller $N^{I I}$ ), the smaller is the effect of trading costs $b$ on $Y^{I}{ }^{7}$

- The ratios to output of imports and exports of intermediates fall with $b$.

- An increase in country size, measured as a rise in $N^{I}$ for given $N^{I I}$, lowers the ratio to GDP of imports and exports of intermediates.

For given country sizes and trading costs, the distorting element in the model comes from the markup pricing of the intermediate goods in the two countries. A social planner for the world, who takes as given the sizes of countries and bears the cost of trade $b$, would price each of these goods at marginal cost, $1 .^{8}$ Output, denoted by $\left(Y^{I}\right)^{*}$, would then be higher than before, corresponding to setting $\mu^{I}=\mu^{I I}=1$ in equation (4):

$$
\left(Y^{I}\right)^{*}=A^{1 /(1-\alpha)} \alpha^{\alpha /(1-\alpha)} N^{I} \cdot\left\{N^{I}+(1-b)^{\alpha /(1-\alpha)} \cdot N^{I I}\right\} .
$$

If the markup ratios are the same in the two countries, $\mu^{I}=\mu^{I I}=$ $\mu$, then the shortfall of production due to markup pricing is given from equations (4) and (9) by

$$
Y^{I} /\left(Y^{I}\right)^{*}=(1 / \mu)^{\alpha /(1-\alpha)}<1 .
$$

In this model, consumption per person (and, hence, the utility of the representative consumer) would be maximized if the entire world consisted of one country, because cross-border transaction costs would then be eliminated. However, this conclusion arises only because we have neglected some costs that tend to rise with the size of a country. In particular, larger political jurisdictions typically have to deal with a more heterogeneous citizenry. The growing heterogeneity makes it increasingly difficult to avoid

7. This effect tends also to apply to $C^{I}$. For example, it goes through if $\mu^{I}=$ $\mu^{I I}$, as in equation $(8)$.

8. For given $\mu^{I I}, \dot{C}^{I}$ is maximized by setting $\mu^{I}$ above unity. The reason is the usual monopoly tariff argument applied here to sales of intermediates to country II. 
polarization and to agree on an efficient set of policies and institutions. ${ }^{9}$ In addition, diseconomies of scale in public administration tend to emerge at some level of country size.

\section{B. Currency Unions and Trading Costs}

The model shows how trading costs $b$ influence the volume of foreign trade and, hence, the levels of production and consumption in each country. In particular, equation (7) shows that a decline in $b$ raises consumption - and, hence, utility-in country $I$. We can readily extend the model to allow for more countries and, thereby, find the positive effect on country $i$ 's consumption $C^{i}$ from a reduction in the trading cost $b_{i j}$, with any other country $j$. One component of the trading cost, $b_{i j}$, consists of shipping costs, which depend on distance and available methods of transportation. Other components involve government regulations, familiarity with foreign rules and business practices, and so on. In addition, trading costs would depend on financial considerations, including currency exchanges. Suppose that we consider two countries, $i$ and $j$, which naturally trade a lot because they are close together, speak the same language, or have other characteristics that reduce trading costs. Then we wish to consider whether this pair of countries would be especially motivated to reduce the financial costs of trading, for example, by adopting a common currency. Implicitly, we are assuming that the adoption of a common currency entails costs (to be detailed later), and we are asking whether countries that naturally trade a lot would be more willing to incur these costs.

Formally, the answer depends on whether the marginal effect of $1-b$ on $C^{I}$, which equation (7) shows to be positive, rises or falls as $1-b$ increases. ${ }^{10}$ If it rises, then countries that naturally have low trading costs (and, hence, high trading volumes) would be more motivated to adopt a common currency. ${ }^{11}$ Otherwise, countries that naturally trade a lot would be less likely to enter into a currency union. Equation (7) implies that the derivative of $C^{I}$ with respect to $1-b$ is given by

9. This kind of trade-off for determining country size is the one emphasized in Barro [1991], Alesina and Spolaore [1997], and Alesina, Spolaore, and Wacziarg [2000].

10. A parallel expression applies for the effect of $1-b$ on $C^{I I}$.

11. The implicit assumption here is that the incremental net cost associated with the adoption of a common currency is not itself a function of $1-b$. 


$$
\frac{\partial C^{I}}{\partial(1-b)} \sim(1-b)^{(2 \alpha-1) /(1-\alpha)}
$$

Hence, the second derivative is positive or negative depending on whether $\alpha$ is greater or less than one-half. If $\alpha>1 / 2$, then the intermediates are relatively close substitutes, and the dominant effect is that a lowering of $b$ saves on the trading costs incurred (which are more important when the volume of trade is large). If $\alpha<1 / 2$, then the intermediates are poor substitutes, and the dominant effect involves the high marginal product of intermediates when the trading cost is high. Thus, to get the expected result-whereby countries that naturally trade a lot would particularly benefit from using a common currency-we have to assume that the underlying tradable goods are relatively close substitutes. In this case, we predict that countries with more bilateral trade are more likely to form currency unions.

We can also examine the effect of country size on the incentive to join a currency union. Equation (7) can be readily shown to imply that, for given $N$,

$$
\frac{\partial}{\partial N^{I}}\left[\frac{\partial C^{I}}{\partial(1-b)}\right]<0 .
$$

Hence, a smaller country (lower $N^{I}$ for given $N$ ) would be more motivated to incur costs to enter into a currency union.

\section{Monetary Policy}

To introduce nominal elements and a possible role for monetary policy, we use a simple setting in which the nominal prices of the intermediate goods involve some stickiness, whereas the prices of the final goods are flexible. More generally, the assumption is that more specialized and, hence, less competitive products tend to feature less flexibility in their nominal prices. For further discussion, see Barro and Tenreyro [2000].

For goods produced in country $I$, let $p_{j}\left(j=1, \ldots, N^{I}\right)$ be the nominal price of the $j$ th intermediate good and $p$ the nominal price of final goods (and, hence, consumer goods), all of which sell at one price. We assume that $p$ is determined through some stochastic process by country I's monetary authority. That is, nominal monetary aggregates-which we do not model explicitly-are assumed to adjust to achieve a target nominal price of final goods. If the nominal prices of the intermediate goods were 
flexible, the preceding analysis would go through, with the relative price of each good, $p_{j} / p$, equated to the markup ratio, $\mu^{I}$.

Suppose, however, that the provider of intermediates in each sector $j$ sets the nominal price $p_{j}$ one period in advance. Then, to find the nominal price that the provider would choose, we have to know the probability distribution of $p$. As a first approximation, the price will be set as

$$
p_{j} \approx \mu^{I} \cdot E p,
$$

where $E p$ is the one-period-ahead expectation of $p$. If $p$ exceeds $E p$, then $p_{j} / p=\mu^{I} .(E p / p)$ falls correspondingly below the intended markup level, $\mu^{I}$, and the demand for country $I$ 's intermediates rises.

Country $I I$ uses a different currency and denominates its prices, $p_{j}^{*}\left(j=N^{I}+1, \ldots, N\right)$ and $p^{*}$, in units of that currency. We assume that $p^{*}$ is determined through some stochastic process by country II's monetary authority. We also assume that the nominal exchange rate, $\epsilon$, between the currencies of countries $I$ and $I I$ is flexible and adjusts so that the standard $P P P$ condition holds:

$$
\epsilon=p / p^{*} \text {. }
$$

This condition is consistent with the assumption that final product is homogeneous and internationally tradable with zero transaction costs.

As in country $I$, the nominal price of each of country $I I$ 's intermediate goods, $p_{j}^{*}$ for $j=N^{I}+1, \ldots, N$, is set one period in advance. The price-setting formula is analogous to that given in equation (12):

$$
p_{j}^{*} \approx \mu^{I I} \cdot E p^{*} .
$$

Therefore, if $p^{*}$ exceeds $E p^{*}$, then $p_{j}^{*} / p^{*}=\mu^{I I} \cdot\left(E p^{*} / p^{*}\right)$ falls correspondingly below the intended markup level, $\mu^{I I}$, and the demand for country $I I$ 's intermediates rises. Note that the nominal price in country I's money of each of country $I I$ 's intermediate goods is given by

$$
p_{j}=\epsilon p_{j}^{*}, \quad \text { for } j=N^{I}+1, \ldots, N .
$$

The $P P P$ condition in equation (13) implies accordingly that the relative price of each of these goods is

$$
p_{j} / p=p_{j}^{*} / p^{*} .
$$


Thus, buyers in both countries face the same relative price for the intermediate goods produced in country $I I$ (and, similarly, for the intermediate goods produced in country $I$ ).

The considerations just discussed bring in real effects from unexpected inflation. Actual inflation may affect the costs of transacting and thereby bring in additional real effects. One set of transactions involves purchases of domestically produced intermediates, which are used to create final product. We assume that the real resources used to carry out these transactions are an increasing function, $\beta(\pi)$, of the domestic inflation rate, $\pi \equiv$ $\log [p(t) / p(t-1)]$. Some of these resources relate to costs of changing prices and others to the use of domestic money to carry out trades. ${ }^{12}$ We model $\beta(\pi)$ as analogous to the iceberg cost $b$ that we assumed previously applied to foreign trade.

The second set of transactions involves purchases of foreignproduced intermediates. We assumed before that the fraction $b$ of these trades would be lost due to iceberg trading costs. We assume now that this trading cost is an increasing function $b\left(\pi^{*}\right)$ of the foreign inflation rate, $\pi^{*} \equiv \log \left[p^{*}(t) / p^{*}(t-1)\right]$. Since purchases of foreign goods involve the use of domestic money for foreign exchange transactions, the cost $b$ might also rise with domestic inflation, $\pi$.

From the standpoint of output in country $I$, the parameter $\mu^{I}$ in equation (4) is replaced by $\mu^{I} \cdot E p / p$ for the $N^{I}$ sectors of country $I$. Analogously, the parameter $\mu^{I I}$ is replaced by $\mu^{I I}$. $E p^{*} / p^{*}$ for the $N^{I I}$ sectors of country $I I$. Moreover, the effective cost of domestic intermediates now includes the effect of the trading cost $\beta$. Therefore, country I's output is given by

$$
\begin{aligned}
Y^{I}=A^{1 /(1-\alpha)} \alpha^{\alpha /(1-\alpha)} N^{I} \cdot\{ & {\left[\left(\frac{1-\beta}{\mu^{I}}\right) \cdot\left(\frac{p}{E p}\right)\right]^{\alpha /(1-\alpha)} \cdot N^{I} } \\
& \left.+\left[\left(\frac{1-b}{\mu^{I I}}\right) \cdot\left(\frac{p^{*}}{E p^{*}}\right)\right]^{\alpha /(1-\alpha)} \cdot N^{I I}\right\} .
\end{aligned}
$$

Equation (15) implies that unexpected inflation in either country raises output in country $I$. (The results are analogous for country II.) The relative strengths of domestic and foreign unexpected inflation on domestic output depend on country sizes, $N^{I}$ and $N^{I I}$,

12. Part of the private cost of transacting would have a reflection in seignorage revenue of the government. If this revenue were remitted to households as lump-sum transfers, then consumption would be affected accordingly. 
adjusted for the trading cost terms, $1-\beta$ and $1-b$. Because of the distortion from the markup pricing of the intermediate goods, unexpected inflation tends to offset the distortion and leads thereby to an efficient expansion of output. The outcomes $p / E p=$ $\mu^{I}>1$ and $p^{*} / E p^{*}=\mu^{I I}>1$ would generate the efficient levels of production in both countries (for given values of $\beta$ and $b$ ). In addition to the effects from unexpected inflation, actual inflation at home and abroad reduces output-by raising $\beta$ and $b$, respectively.

The formula for consumption in equation (7) is similarly modified by replacing $\mu^{I}$ by $\mu^{I} \cdot E p / p$ and $\mu^{I I}$ by $\mu^{I I} \cdot E p^{*} / p^{*}$. The term involving $\left(\mu^{I}-\alpha\right) \cdot N^{I}$ is now also multiplied by $(1-\beta)^{\alpha /(1-\alpha)}$. This equation implies a relation between $C^{I} / N^{I}-$ and, hence, utility of the representative agent in country $I$-and unexpected and actual inflation in country $I$, given the behavior of inflation in country $I I$. We provide here a heuristic discussion of this relation.

A positive value for $p / E p$ offsets the distorting effect from the markup $\mu^{I}$ and tends, accordingly, to raise $C^{I} / N^{I}$. However, there are two reasons why too much unexpected inflation would be unattractive. First, the formula in equation (15) assumes that producers of intermediates always meet demands, regardless of the realizations of $p$ and $p^{*}$. However, if $p / E p>\mu^{I}$, then the real price of produced intermediates in country $I$ falls short of the unit cost of production. Given the constant-cost assumption, the producers lose money on each unit produced and sold. If the producers nevertheless meet the demand, then the output of country $I$ intermediates is inefficiently high-and, for this reason, $C^{I} / N^{I}$ declines in this range with $p / E p$. Alternatively, if the producers shrink output to zero to avoid losses on each unit produced, then no intermediates are produced in country $I$ and output decreases drastically (in an inefficient manner). Similar considerations apply to unexpected inflation in country $I I$.

Another consideration involves the negative effect of unexpected inflation on the profits of the producers of intermediate goods in country $I$. For sales of these intermediates within country $I$, unexpected inflation leads to a transfer of income from producers to consumers. Given the assumption that ownership rights in domestic firms are uniformly distributed across the domestic households, this transfer does not affect the consumption of the representative household in country $I$. Thus, from this domestic perspective, a policy-maker in country $I$ would value 
unexpected inflation up to the point where $p / E p=\mu^{I}>1$. However, the marginal benefit (in terms of the increase in $C^{I} / N^{I}$ ) from increases in $p / E p$ can be shown to decrease as $p / E p$ rises toward $\mu^{I}$.

With respect to sales of country I's intermediates to country $I I$, the loss of monopoly profits is not compensated by any benefits to domestic residents. Therefore, this consideration reduces the net effect of unexpected domestic inflation on $C^{I} / N^{I}$. In particular, $C^{I} / N^{I}$ starts to fall with unexpected inflation before $p / E p$ reaches $\mu^{I}$.

From the standpoint of the policy-maker for any country $i$, the model rationalizes a loss function in which some amount of unexpected inflation (for prices of final product), $\pi_{i}-\pi_{i}^{e}$, reduces the loss. This effect diminishes with the size of $\pi_{i}-\pi_{i}^{e}$, eventually becomes nil, and subsequently changes sign. The amount of the initial loss reduction and the size of the interval over which unexpected inflation is beneficial depends on the markup ratios, $\mu^{I}$ and $\mu^{I I}$ (see equation (7)). In particular, if we view the markup ratios as varying over time, then the policy-maker of country $i$ values unexpected inflation more when $\mu_{i}$ is higher.

Given the behavior of unexpected inflation, actual inflation at home raises the domestic trading cost $\beta$, and perhaps also the foreign trading cost $b$, and thereby reduces consumption. From the standpoint of a loss function, we would therefore write the loss as an increasing function of actual inflation at home.

\section{Independent Monetary Policy under Discretion}

We approximate the results from the model by assuming that the objective of monetary policy in country $i$ can be described by the minimization of a loss function that involves actual and unexpected inflation at home:

$$
\mathscr{L}_{i}=a \pi_{i}+(\gamma / 2) \cdot\left(\pi_{i}\right)^{2}+(\theta / 2) \cdot\left[\phi \cdot\left(\pi_{i}-\pi_{i}^{e}\right)-z_{i}-\eta_{i}\right]^{2} .
$$

We think of this loss as corresponding (with a negative sign) to the proportionate value of domestic consumption per person, as determined in the model. The loss applies for given behavior of inflation in other countries.

The first two terms in equation (16) form a quadratic in actual inflation, $\pi_{i}$. If $a>0$ and $\gamma \geq 0$, then the marginal cost of 
actual inflation is positive. ${ }^{13}$ If $\gamma>0$, then the marginal cost of actual inflation is increasing.

The key term is the second one, $(\theta / 2) \cdot\left[\phi \cdot\left(\pi_{i}-\pi_{i}^{e}\right)-z-\right.$ $\left.\eta_{i}\right]^{2}$, where $\theta>0, \phi>0, z_{i}>0$, and $\eta_{i}$ is an error term with zero mean, serial independence, and constant variance $\sigma_{n_{i}}^{2}$. This term, which looks like an expectational Phillips curve, is intended to approximate the results from the model. Specifically, if $\eta_{i}=0$, then unexpected inflation, $\pi_{i}-\pi_{i}^{e}$, initially reduces the loss, $\mathscr{L}_{i}$. However, the marginal benefit diminishes and eventually changes sign, when $\pi_{i}-\pi_{i}^{e}$ reaches $z_{i}$. The parameter $z_{i}$ is increasing in the average markup ratio, $\mu_{i}$. The error term $\eta_{i}$ corresponds to movements of the markup ratio, $\mu_{i}$, away from its mean value. A higher value of $\eta_{i}$ (higher value of $\mu_{i}$ ) raises the initial benefit from unexpected inflation and expands the interval over which this benefit is positive. ${ }^{14}$

Country $i$ can conduct monetary policy on its own or anchor to another country. On its own, the inflation rate is determined in a discretionary manner each period to minimize $\mathscr{L}_{i}$, as defined in equation (16). The solution for the discretionary equilibrium, which follows the approach of Barro and Gordon [1983], is

$$
\hat{\pi}_{i}=-\frac{a}{\gamma}+\frac{\theta \phi z}{\gamma}+\frac{\theta \phi \eta_{i}}{\left(\gamma+\theta \phi^{2}\right)} .
$$

Using equations (16) and (17), we obtain

$$
E \hat{\mathscr{L}}_{i}=\frac{1}{2} \cdot\left[-\frac{a^{2}}{\gamma}+\theta z^{2}+\frac{(\theta \phi z)^{2}}{\gamma}+\frac{\theta \gamma \sigma_{\eta_{i}}^{2}}{\gamma+\theta \phi^{2}}\right] .
$$

If the monetary authority could commit inflation at least one period ahead, then the inflation rate would be reduced by the inflation-bias term, $\theta \phi z / \gamma$. The term $(\theta \phi z)^{2} / \gamma$ in equation (18) reflects these costs.

13. The dependence of the loss function on actual inflation can also be viewed as incorporating public-finance benefits from seignorage revenues. In this context, $a<0$ may apply, in which case the marginal cost of actual inflation would be negative at low values of $\pi_{i}$.

14. An additional benefit of surprise inflation could reflect effects on the real value of nominal obligations, for example, of government debt denominated in domestic currency. With distorting taxation, these kinds of capital levies would be valued, because they would reduce the distortions from other sources of revenue. In this case, $z_{i}$ would rise with the government's stock of nominal debt. A positive $\eta_{i}$ could represent a situation in which this type of capital levy is especially attractive, perhaps because of an emergency that motivates temporarily high levels of public spending. 


\section{E. Outcomes under Dollarization}

Consider now a potential anchor country, denoted by the subscript $j$. We assume that this country has the same underlying preference and cost parameters as country $i$; that is, the parameters in equation (16) are the same. Specifically, we assume that $z_{j}=z_{i}$ (so that average markups are the same) but allow for a shock, $\eta_{j}$, that can differ from $\eta_{i}$. The monetary authority of country $j$ can commit at least one period ahead and picks an optimal contingent rule to minimize the prior expectation of $\mathscr{L}_{j}$. The inflation rate in country $j$ is given by

$$
\pi_{j}^{*}=-\frac{a}{\gamma}+\frac{\theta \phi \eta_{j}}{\left(\gamma+\theta \phi^{2}\right)} .
$$

Note that country $j$ 's monetary authority reacts to its own disturbance, $\eta_{j}$, which we assume to be serially independent with zero mean and constant variance $\sigma_{\eta_{j}}^{2}$. However, $\eta_{j}$ need not be independent of $\eta_{i}$.

Suppose now that country $i$ irrevocably adopts country $j$ 's currency. We assume that it is institutionally much more costly to renege on a dollarization commitment than on a monetary policy rule. Thus, even though country $i$ cannot make a binding commitment to a policy rule, it can make an irrevocable commitment to give up its currency.

In the case of currency adoption, $\pi_{i}$ would equal $\pi_{j}^{*}$ plus the rate of change of the price of a market basket of final goods in country $i$ expressed relative to that in country $j$. In the model, there was only one type of final product, and this product could be traded internationally with zero transaction costs. In this case, $\pi_{i}$ would equal $\pi_{j}^{*}$. We now generalize to allow the countries to produce different market baskets of final goods, and we assume that the rate of change of the price of country $i$ 's basket relative to country $j$ 's is given by an exogenous, random error term, $\epsilon_{i j}$. This shock is taken to be serially independent with zero mean and constant variance $\sigma_{\epsilon}^{2}$ and to be distributed independently of $\eta_{i}$ and $\eta_{j}$. Hence, under dollarization, country $i$ 's inflation rate is given by

$$
\pi_{i}^{j}=-\frac{a}{\gamma}+\frac{\theta \phi \eta_{j}}{\left(\gamma+\theta \phi^{2}\right)}+\epsilon_{i j}
$$

The $j$ superscript indicates that the outcome applies for country $i$ under anchoring to country $j$. 
If country $i$ no longer issues its own currency, then it would lose seignorage income. The corresponding income accrues instead to country $j$. We assume, for now, that the anchor returns to country $i$ the full amount of the seignorage obtained in country $i$. In this case, the anchor country has no incentive to change its policy regardless of what country $i$ chooses.

With inflation determined from equation (20), country $i$ 's expected net costs of inflation are given from equation (16) by

$$
\begin{aligned}
E \mathscr{L}_{i}^{j}=-\frac{a^{2}}{2 \gamma}+\frac{\theta z^{2}}{2}+ & \frac{\left(\gamma+\theta \phi^{2}\right) \cdot \sigma_{\epsilon}^{2}}{2} \\
& +\frac{\theta^{2} \phi^{2} \sigma_{\eta_{j}}^{2}}{2\left(\gamma+\theta \phi^{2}\right)}+\frac{\theta \sigma_{\eta_{i}}^{2}}{2}-\frac{\theta^{2} \phi^{2} \operatorname{cov}\left(\eta_{i}, \eta_{j}\right)}{\gamma+\theta \phi^{2}} .
\end{aligned}
$$

The covariance between $\eta_{i}$ and $\eta_{j}$ appears in equation (21) because it determines the extent to which country $j$ 's adjustments to its own disturbances, $\eta_{j}$, are helpful for country $i$. This criterion neglects any impact of dollarization on trading costs. In Section III we combine trading costs with monetary policy effects in a general discussion of optimal currency areas.

\section{F. The Choice of Whether to Dollarize}

We assess here the choice of currency regime based on a comparison of the monetary and inflation policies that result. The difference between $E \hat{\mathscr{L}}_{\mathbf{i}}$ from equation (18) and $E \mathscr{L}_{i}^{j}$ from equation (21) is given by ${ }^{15}$

$$
\begin{aligned}
\Delta \mathscr{L}^{i j} \equiv E \hat{\mathscr{L}}_{i}-E \mathscr{L}_{i}^{j}=\frac{(\theta \phi z)^{2}}{2 \gamma} \\
-\frac{1}{2} \cdot\left[\left(\gamma+\theta \phi^{2}\right) \cdot \sigma_{\epsilon}^{2}+\left(\frac{\theta^{2} \phi^{2}}{\gamma+\theta \phi^{2}}\right) \cdot \operatorname{var}\left(\eta_{i}-\eta_{j}\right)\right]
\end{aligned}
$$

A positive value for $\Delta \mathscr{L}^{i j}$ indicates that the independent regime is more costly for country $i$ than the system with anchoring to country $j$. Hence, anything that raises the terms on the righthand side of the equation favors dollarization. The first term, $(\theta \phi z)^{2} / 2 \gamma$, is the cost associated with the inflation bias under a

15. The underlying model assumed that neither the discretionary domestic authority nor the committed anchor made purely random mistakes in their choices of inflation. If such errors were introduced, then equation (22) would include an additional term to reflect the difference in variances of the two policy errors. 
discretionary regime in country $i$. The linkage to the committed country $j$ avoids these costs and thereby favors dollarization. The second term, which involves $\sigma_{\epsilon}^{2}$, derives from the random shifts in relative prices between countries $i$ and $j$. Since country $i$ receives country $j$ 's inflation rate only up to the random error, $\epsilon_{i j}$, a higher value for $\sigma_{\epsilon}^{2}$ makes dollarization less attractive. The third term, which contains $\operatorname{var}\left(\eta_{i}-\eta_{j}\right)$, reflects the benefits from an independent monetary policy, in the sense that $\pi_{i}$ can react to $\eta_{i}$ in the autonomous regime. The extent of this benefit depends on how closely $\eta_{j}$ moves with $\eta_{i}$. Equation (22) shows that the variance of $\eta_{i}-\eta_{j}$ is what matters for the comparison between the regimes.

Note that we have assumed that the variances of relative prices, $\epsilon_{i j}$, and output shocks, $\operatorname{var}\left(\eta_{i}-\eta_{j}\right)$, are independent of the monetary regime. If the adoption of a currency union reduces these variances, then equation (22) underestimates the benefit of currency adoption.

\section{EXTENSIONS}

\section{A. Simple Rules}

The analysis assumes that country $j$ commits to the contingent rule for $\pi_{j}$ that minimizes the prior expectation of $\mathscr{L}_{j}$. However, one may argue that commitment is difficult to verify and, hence, maintain when it involves these sorts of contingent reactions of $\pi_{j}$ to $\eta_{j}$. In our model, the contingent rule is easy to implement and verify, but matters are more complicated if shocks are not immediately and universally observable.

Assume that country $j$ can follow discretion or commit to a simple rule that precludes feedback from $\eta_{j}$ to $\pi_{j}$. In this case, $\pi_{j}$ would be set to the constant $-a / \gamma .{ }^{16}$ One can easily show that an anchor following a single rule is more attractive to the client, if

$$
\sigma_{\eta_{j}}>2 \rho_{i j} \sigma_{\eta i},
$$

where $\rho_{i j}$ is the correlation (under the dollarized regime) between $\eta_{i}$ and $\eta_{j}$. Thus, if $\sigma_{n_{i}}=\sigma_{n_{j}}$, then if $\rho_{i j}<1 / 2$, country $j$ is a more attractive anchor if it follows the simple rule.

16. In this situation, country $j$ might prefer discretion to the simple rule. Discretion allows for flexible responses of $\pi_{j}$ to $\eta_{j}$, whereas the simple rule precludes these reactions. 


\section{B. Seignorage Flows and Adjustments by the Anchor Country}

If the seignorage generated by clients were kept by the anchor, then the anchor's choice of inflation, $\pi_{j}$, would change. In the range where seignorage is an increasing function of inflation, the anchor would be motivated to select higher inflation than otherwise.

The allocation of seignorage can be part of a more general contractural arrangement between clients and anchors. ${ }^{17} \mathrm{An}$ allowance for allocations of seignorage or other transfers between countries introduces the potential for an anchor to adjust its monetary policy to align better with the interests of its clients. We explore here whether a system of transfers can make an adjustment of the anchor's policy mutually beneficial. ${ }^{18}$

The net cost of inflation, $\mathscr{L}_{i}$, from equation (16), applies as a fraction of country $i$ 's consumption, $C_{i}$. If we take the universe as the anchor country $j$ and one linking country $i$, then the total net cost due to inflation, expressed as a share of the combined consumptions, $C_{j}+C_{i}$, is

$$
\mathscr{L}=\tau_{j} \mathscr{L}_{j}+\tau_{i} \mathscr{L}_{i},
$$

where $\tau_{j} \equiv C_{j} /\left(C_{j}+C_{i}\right)$ and $\tau_{i} \equiv C_{i} /\left(C_{j}+C_{i}\right)$. We assume now that the anchor determines its policy rule to minimize the prior expectation of $\mathscr{L}$, rather than $\mathscr{L}_{j}$, as assumed before. The $\mathscr{L}$ objective weighs foreigners' net costs equally with those of domestic residents. Such an objective would emerge in equilibrium from competition among anchor countries, assuming that clients effectively compensate the anchor for deviating from policies that are otherwise best for the anchor's domestic residents.

Let the anchor's policy rule be designated by

$$
\pi_{j}=v+v_{j} \eta_{j}+v_{i} \eta_{i}+v_{\epsilon} \epsilon_{i j}
$$

where $\left(\mu, \nu_{j}, \nu_{i}, \nu_{\epsilon}\right)$ are the feedback coefficients chosen by the monetary authority. ${ }^{19}$ These coefficients are given by

$$
\nu=-\frac{a}{\gamma}
$$

17. In the European Monetary Union, for instance, the seignorage revenue is allocated in proportion to the members' GDP shares.

18. A complex political game may be involved in the fixing and implementation of these schemes. This game is not modeled here.

19. Note that we have returned to the setting in which country $j$ can commit to a contingent rule in the sense of committing to the coefficients shown in equation (24). 


$$
\begin{aligned}
& v_{j}=\tau_{j} \cdot\left(\frac{\theta \phi}{\gamma+\theta \phi^{2}}\right), \\
& \nu_{i}=\tau_{i} \cdot\left(\frac{\theta \phi}{\gamma+\theta \phi^{2}}\right), \\
& v_{\epsilon}=-\tau_{i} .
\end{aligned}
$$

The constant term, $v=-a / \gamma$, is the same as before. Country $j$ 's response, $v_{j}$, to its own disturbance, $\eta_{j}$, is the same as before, except that the coefficient is attenuated by multiplication by the consumption share $\tau_{j}$. Correspondingly, the anchor's choice of inflation, $\pi_{j}$, now reacts in accordance with the coefficient $v_{i}$ to country $i$ 's disturbance, $\eta_{i}$. This response depends on country $i$ 's consumption share, $\tau_{i}$. The coefficient $v_{\epsilon}=-\tau_{i}$ means that country $j$ 's monetary authority partly offsets an increase in relative prices in country $i$ by lowering $\pi_{j}$. The extent of the offset is given by $\tau_{i}$, the share of country $i$ 's consumption.

Consider now the compensation that country $i$ must pay to country $j$. On its own, country $j$ chooses the inflation rate $\pi_{j}^{*}$ given in equation (19). With the accommodation to country $i$, country $j$ chooses the inflation rate $\pi_{j}$ given by equations (24) and (25). The amount that country $j$ loses from the accommodation can be calculated by looking at the difference in expected costs, $\mathscr{L}_{j}$, associated with the two choices of inflation. The result is

(26) Cost of accommodation $=\frac{1}{2}\left(\tau_{i}\right)^{2} \cdot\left\{\left(\gamma+\theta \phi^{2}\right) \cdot \sigma_{\epsilon}^{2}\right.$

$$
\left.+\left(\frac{\theta^{2} \phi^{2}}{\gamma+\theta \phi^{2}}\right) \cdot \operatorname{var}\left(\eta_{i}-\eta_{i}\right)\right\}
$$

Suppose that country $i$ can choose whether to link to country $j$, that country $j$ accommodates its inflation choice to the presence of country $i$ (as implied by equations (24) and (25)), and that country $i$ pays the necessary compensation. The level of compensation is the amount shown in equation (26) multiplied by $C_{j}$. The criterion for country $i$ to dollarize is then modified from equation (22) to

$$
\begin{aligned}
\Delta \mathscr{L}^{i j}=\frac{(\theta \phi z)^{2}}{2 \gamma}- & \frac{\tau_{j}}{2} \\
& \times\left\{\left(\gamma+\theta \phi^{2}\right) \cdot \sigma_{\epsilon}^{2}+\left(\frac{\theta^{2} \phi^{2}}{\gamma+\theta \phi^{2}}\right) \cdot \operatorname{var}\left(\eta_{i}-\eta_{j}\right)\right\}
\end{aligned}
$$


The new element in equation (27) is that the terms involving $\sigma_{\epsilon}^{2}$ and $\operatorname{var}\left(\eta_{i}-\eta_{j}\right)$ are smaller in magnitude than before because they are multiplied by $\tau_{j}$, which is less than one. These terms are smaller because country $j$ 's partial adjustment of $\pi_{j}$ for country $i$ 's disturbances makes these disturbances less costly for country $i$ (even after considering the compensation that country $i$ pays to country $j$ ).

A smaller value for $\tau_{j}$ makes dollarization more attractive, because it reduces the compensation that country $i$ must pay. In the model, a small anchor country is as good as a large one, because the commitment technology is independent of size. However, for a larger anchor country, the costs of accommodating to country $i$ are greater, since the term in equation (26) applies over a larger scale, $C_{j}$.

This conclusion changes if the capacity to maintain a commitment depends on the relative economic sizes of the anchor country and its clients. For example, consider a large country, such as Russia, using a small one, say Estonia, as an anchor. This arrangement may not work because ex post pressure from Russia to create "unanticipated" inflation could be too much for Estonia to bear. In other words, anchors that are larger in relation to their clients may be more solid because they can better withstand ex post pressures to be time inconsistent.

\section{Number of Countries ANd of CURREncies}

\section{A. The Setup}

We now combine issues of trade and monetary policy to investigate the equilibrium number of currency unions in a world composed of an exogenous number of independent countries. To keep things simple, we return to the case of no compensation from clients to anchors.

In this situation, the criterion for country $i$ to prefer linkage to country $j$ over autonomy as shown above is given by

$$
\begin{aligned}
\Delta \mathscr{L}^{i j}=\frac{(\theta \phi z)^{2}}{2 \gamma} & -\frac{1}{2} \\
& \times\left\{\left(\gamma+\theta \phi^{2}\right) \cdot \sigma_{\epsilon}^{2}+\left(\frac{\theta^{2} \phi^{2}}{\gamma+\theta \phi^{2}}\right) \cdot \operatorname{var}\left(\eta_{i}-\eta_{j}\right)\right\}>0 .
\end{aligned}
$$

Recall that this criterion assumes that country $j$ follows a com- 
mitted policy, whereas country $i$ would, on its own, follow a discretionary policy. Hence, the first element in the choice about currency unions is whether a country can commit its monetary policy. We assume that there are two types of countries: the indicator $\lambda_{i}$ takes the value of 1 if country $i$ can make binding commitments and 0 if it cannot. We treat this commitment ability as exogenous: it derives from historical and institutional factors, such as a legal commitment to central bank independence.

The second element concerns the distribution parameters for the disturbances in equation (28). Linkage is more attractive the lower the variances of relative prices and output shocks, $\sigma_{\epsilon}^{2}$ and $\operatorname{var}\left(\eta_{i}-\eta_{j}\right)$, under the dollarized system. We focus here on a key factor that would influence these distribution parameters, the extent to which countries $i$ and $j$ are linked by trade. We assume that more trade reduces $\sigma_{\epsilon}^{2}$ and $\operatorname{var}\left(\eta_{i}-\eta_{j}\right){ }^{20}$

Equations (5) and (6) imply that the trading volume between countries $i$ and $j$ depends inversely on the trading cost parameter, which we denote by $b_{i j}$. Following the empirical gravity literature, we posit that $b_{i j}$ increases with the distance between the countries. Empirically, the concept of distance captures physical distance and other factors, such as language, colonial history, and sharing a border. We assume that these various concepts of distance can be captured by a single dimension, which we arrange on a line segment that represents the world. Formally, if $D_{i j}$ is the distance between the midpoints of countries $i$ and $j$, then $b_{i j}$ increases with $D_{i j}$, and the volume of trade declines with distance. If the trade volume between two countries increases, then the variances $\sigma_{\epsilon}^{2}$ and $\operatorname{var}\left(\eta_{i}-\eta_{j}\right)$ decrease, thereby making a currency union more attractive. In addition, even holding trade shares constant, a reduction in distance may increase the comovements between two economies-think, for instance, of weather patterns and region-specific shocks.

If the adoption of a common currency reduces trading costs, then we found before that the currency linkage has a direct positive effect on trade, output, and consumption. Equation (7) implies that the effect of the trading cost with country $j$ on the consumption of country $i$ is given by

20. See Imbs [2000] for a review of the literature on how trade affects comovements of output as for new results. Engel and Rose [2000] investigate determinants of the variances of relative prices, as measured by real exchange rates. 


$$
\frac{\partial C^{i}}{\partial\left(1-b_{i j}\right)}=H N_{j} \cdot\left(1-b_{i j}\right)^{(2 \alpha-1) /(1-\alpha)},
$$

where $H$ is a positive constant and $N_{j}$ is the size of country $j$. Thus, as noted before, if $\alpha>1 / 2$, then a lower trading cost-due, say, to a smaller distance $D_{i j}$-raises the marginal gain to a further reduction in trading costs. Therefore, if $\alpha>1 / 2$, the direct trade effect provides another reason for smaller distance to favor dollarization.

Equation (29) implies that the trade benefits of country $i$ adopting the currency of country $j$ are also increasing in $N_{j}$, the size of country $j$. More generally, this size measure would correspond to the size of the currency union of which country $j$ is already a part. We denote this size by $N_{j}^{u}$, where $N_{j}^{u}=N_{j}$ if country $j$ is linked to no other countries.

In summary, the previous discussion suggests that linkage to country $j$ implies that country $i$ 's consumption changes first by $\Delta \mathscr{L}^{i j}$, given by equation (28), and second, by the trading-cost effect given by equation (29). We can write the overall change in consumption, denoted by $\Delta G^{i j}$, as the function,

$$
\Delta C^{i j}=\Gamma\left(\lambda_{j}-\lambda_{i}, D_{i j}, N_{j}^{u}\right),
$$

where $\Gamma(\cdot)$ increases with $\lambda_{j}-\lambda_{i}$ and $N_{j}^{u}$ and falls with $D_{i j}$.

We are interested in an equilibrium defined as follows.

Definition. An equilibrium is a configuration of currency unions in which no country belonging to a union would like to leave the union to have its own currency or to join another union. In addition, no country not belonging to a union would like to join one.

We begin by imposing some structure on the problem.

\section{B. Currency Unions in Equilibrium}

Assume that the world consists of $M$ countries of equal size $N=$ $1 / M$. Obviously, countries for which $\lambda=1$ have a comparative advantage at providing the currencies used in multicountry currency unions. ${ }^{21}$ Suppose that there are $M$ countries, numbered from 1 to $M$ from left to right, and that $\lambda_{k}=\lambda_{h}=1$, with $1 \leq k<h \leq M$, and $\lambda_{i}=0$ for $i \neq k, h$. The following describes the equilibria:

21. In fact, one can easily show that the largest $D_{i j}$ for which country $i$ would adopt the currency of country $j$ is larger if $\lambda_{j}=1$ than if $\lambda_{j}=0$. 
Configuration of EQULIBRIA. If countries $i$ and $i+2$ belong to the same currency union, so does country $i+1$.

If $\Gamma\left(0, D_{i j}, N^{u}\right)<0$ for all $i_{j} j$ and any $N^{u}$, then the possible configurations are 1) $M$ currencies in the world, no currency unions; 2) two currencies in the world, those of countries $k$ and $h$; if $k-1=M-h$, then the two currency unions include an equal number of countries, $m=M / 2$; 3) two multicountry currency unions adopting currencies $k$ and $h$, composed, respectively, of $m_{k}$ and $m_{h}$ countries. The remaining $\left(M-m_{h}-m_{k}\right)$ countries all have their own currency. If $k-1=M-h$, then $m_{k}=m_{h}$.

If $\Gamma\left(0, D_{i j}, N^{u}\right) \gtrless 0$, depending on $i, j$ and $N^{u}$, then the additional possible configurations are as follows: 4) all the countries adopt one currency, either that of country $k$ or country $h$; 5) $\zeta>2$ multicountry currency unions that include a total of $M^{\prime} \leq M$ countries.

The first statement implies that currency unions are formed by adjacent countries. Remember that being adjacent in our model implies not only being closer in distance but also trading more and having more correlated shocks. The sufficient condition that isolates the first three cases implies that the only countries that want to adopt a currency other than their own are $\lambda=0$ countries, which may adopt the currency of a committed anchor. This condition tends to be satisfied if the main reason to enter a currency union is to obtain the policy commitment of the anchor. That is, the first term on the left side of equation (30) is dominant. Also, if the benefits from trade arising from sharing the same currency are relatively small, then not much is gained by $\lambda=0$ countries (or $\lambda=1$ countries) in giving up an independent monetary policy. A third factor that would work in favor of satisfying this condition is a high value of $\operatorname{var}\left(\eta_{i}-\right.$ $\eta_{j}$ ) or $\sigma_{\epsilon}^{2}$, for given trade shares. Case 2 is a situation in which all the countries belong to one of two currency unions. This outcome tends to emerge when country shocks are similar or the trade benefits from belonging to a union are high. In case 3 some of the countries with $\lambda=0$ are too far from countries $k$ and $h$ and their currency unions to join either union.

If $\Gamma\left(0, D_{i j}, N^{u}\right)>0$ for some configurations of parameter values, then some countries may want to form a union even without the benefit of commitment. This outcome arises if the trade gains are sufficient to compensate for the loss of monetary autonomy. In this situation, two or more noncommitted countries may form their own union, because they are too far from a $\lambda=1$ country. For instance, 
consider two countries with $\lambda=0$ bordering each other but far from any country with $\lambda=1$. These countries may form a currency union if the trade benefits are sufficiently high and the benefit of commitment comes at too high a price because of the great distance of the closest $\lambda=$ 1 country. An analogous argument applies to countries with $\lambda=1$. Thus, two additional possibilities emerge. In case 4 all the countries adopt the same currency, either of country $k$ or $h$. In case 5 some countries other than $k$ and $h$ form their own multicountry currency unions. An interesting example is the discussion about a monetary union in Central America as an alternative to dollarization.

\section{Many Countries and Few Currencies}

As the number of countries increases, the equilibrium number of currencies may go up less than proportionally with the number of countries or may even decrease.

Consider the following example with three countries, numbered as 1,2,3 from left to right. The countries are each of size 1 and are evenly spaced, so that $D_{12}=D_{23}=1$. Suppose that $\lambda_{1}=\lambda_{3}=1$ and $\lambda_{2}=0$ and that each country has its own currency. This configuration means that country 2 prefers autonomy over linkage to one of the other countries, which implies from equation (30) that ${ }^{22}$

$$
\Gamma(1,1,1)<0 \text {. }
$$

Suppose now that country 2 splits exogenously into two equal-sized countries, labeled from left to right as $2 a$ and $2 b$. These countries are each of size $1 / 2$, and the distances are now, say, $D_{1,2 a}=D_{2 b, 3}=3 / 4$ and $D_{2 a, 2 b}=1 / 2$. In the new situation, countries $2 a$ and $2 b$ may find it attractive to adopt the currencies of countries 1 and 3 , respectively. For example, country $2 a$ prefers the use of country 1's currency over autonomy if

$$
\Gamma(1,3 / 4,1)>0 .
$$

Conditions (31) and (32) can both be satisfied, because $\Gamma(1,3 / 4,1)>$ $\Gamma(1,1,1)$. Furthermore, country $2 a$ does not want to adopt the currency of $2 b$ instead of that of 1 if

$$
\Gamma(1,3 / 4,1)>\Gamma(0,1 / 2,1 / 2) .
$$

This condition can be satisfied together with the previous two, but

22. It follows immediately that it is not in the interest of countries 1 and 3 to form a currency union without country 2 . We are assuming that a three-country currency union is not an equilibrium. 
it is not satisfied for all parameter values, because $D_{2 a, 2 b}<$ $D_{1,2 a}$. Analogous considerations apply to country $2 b$ and its decision to adopt the currency of country 3 .

This example shows that the disintegration of an existing country can move the world from an equilibrium with three countries and two currencies to one with an equilibrium with four countries and two currencies. That is, an increase in the number of independent countries may result in a reduction of the absolute number of independent monies. The example with three countries can be readily generalized to any number of countries.

\section{Disjoint Unions}

In the previous example, the currency unions are formed by adjacent countries. If we interpret distance in terms of geography, then this pattern seems to apply to some real world situations, such as the European Union, the CFA Franc zone in Africa, and the Eastern Caribbean Currency Area. However, the pattern differs in other cases. For example, Panama, El Salvador, and Ecuador have or are about to adopt the dollar, whereas Mexico has not. Similarly, it may be in the interests of Latvia and Estonia to link to the euro, although it may not be worthwhile for Poland.

A number of factors can lead to unions that are not compact. One is differing sizes of countries. Another is differences in comovements that are not explained by distance. Finally, we have assumed that a single dimension of distance exists, but this concept need not correspond to geographical distance.

Another dimension in which countries differ is in their location in the world. A country at the extreme of the line segment is relatively farther from more countries than a country located in the middle. Ceteris paribus, a country in the middle is a more likely anchor than a country at the extremes. Therefore, a small uncommitted country at the "borders" of the world is the least likely anchor, whereas a large committed country in the middle is the most likely anchor. Obviously, the real world is not a line segment and these observations have to be interpreted cum grano salis, but the point is that New Zealand may be a less likely anchor than Switzerland, not only because of the different inflationary histories of the two countries but also because of their geographical locations.

\section{Conclusions}

Currency unions have several real and monetary effects. To the extent that trading costs are lowered by a common currency, 
the formation of a currency union leads to gains in output and consumption. The loss of monetary flexibility has costs and benefits. On the one hand, a country that gives up its currency loses a stabilization device targeted to domestic shocks; on the other hand, the country may gain credibility and thereby reduce undesired inflation. We have shown how the determination of optimal currency areas depends on a complex web of variables and interactions, including the sizes of countries, their distances, the levels of trading costs, the correlations between shocks, and on institutional arrangements that determine how seignorage is allocated and whether transfers between members of a union are feasible. The type of country with the strongest incentive to give up its own currency is one that has a history of high inflation and is close in a variety of ways to a large and monetarily stable country.

As the number of countries increases, their average size decreases, and the volume of international transactions rises. As a result, more and more countries will find it profitable to give up their independent currency. We have shown that, as the number of countries increases, the number of currencies may not only increase less than proportionately but may even fall. This result highlights an important empirical implication of our model. An increase in the number of countries-such as the one seen in the post-World War II period-implies an increase in the number of countries adopting other countries' currencies. The failure to see this pattern on a large scale until recently may reflect the value that governments attach to an independent money as a symbol of sovereignty. However, recent global movements toward currency unions suggest that this symbolic role of currencies may be weakening.

HARVARD UNIVERSITY

\section{REFERENCES}

Alesina, Alberto, and Vittorio Grilli, "The European Central Bank: Reshaping Monetary Policy in Europe," in M. Canzoneri, V. Grilli, and P. Masson, eds., Establishing a Central Bank: Issues in Europe and Lessons from the U. S. (Cambridge, UK: Cambridge University Press, 1992).

Alesina, Alberto, and Enrico Spolaore, "On the Number and Size of Nations," Quarterly Journal of Economics, CXII (1997), 1027-1056.

Alesina, Alberto, Enrico Spolaore, and Romain Wacziarg, "Economic Integration and Political Disintegration," American Economic Review, XC (2000), $1276-1296$.

Anderson, James, and Eric van Wincoop, "Gravity with Gravitas: A Solution to the Border Puzzle," unpublished, Boston College, 2000.

Barro, Robert, "Small is Beautiful," The Wall Street Journal (1991).

Barro, Robert, and David Gordon, "Rules, Discretion, and Reputation in a Model of Monetary Policy," Journal of Monetary Economics, XXI (1983), 101-121. 
Barro, Robert, and Silvana Tenreyro, "Closed and Open Economy Models of Business Cycles with Marked Up and Sticky Prices," National Bureau of Economic Research, Working Paper No. 8043, December 2000.

Bayoumi, Tamim, "A Formal Model of Optimal Currency Areas," IMF Staff Papers (1994).

Dixit, Avinash, and Joseph Stiglitz, "Monopolistic Competition and Optimum Product Diversity," American Economic Review, LXVII (1977), 297-308.

Engel, Charles, and Andrew Rose, "Currency Unions and International Integration," unpublished, University of California at Berkeley, 2000.

Ethier, Wilfred, "National and International Returns to Scale in the Modern Theory of International Trade," American Economic Review, LXXII (1982), 389-405.

Frankel, Jeffrey, and Andrew Rose, "An Estimate of the Effect of Common Currencies Unions on Trade and Income," Quarterly Journal of Economics, CXVII (2002), 437-466.

Giavazzi, Francesco, and Alberto Giovannini, Limiting Exchange Rate Flexibility (Cambridge, MA: MIT Press, 1989).

Glick, R., and Andrew Rose, "Does a Currency Union Affect Trade? The Time Series Evidence," unpublished, University of California at Berkeley, 2001.

Helliwell, John, How Much Do National Borders Matter? (Washington, DC: Brookings Institution Press, 1998).

Hooper, P., and S. Kohlhagen, "The Effect of Exchange Rate Uncertainty on Prices and Volume of International Trade," Journal of International Economics, XII (1978), 483-511.

Imbs, Jean, “Co-Fluctuations," unpublished, London Business School, 2000.

International Monetary Fund, "Exchange Rate Volatility and World Trade," Occasional Paper No. 28, 1984.

Kenen, Peter, and Dani Rodrik, "Measuring and Analyzing the Effects of ShortTerm Volatility in Real Exchange Rates," Review of Economics and Statistics, LXVIII (1986), 311-315.

McCallum, John, "National Borders Matter: Canadian-U. S. Regional Trade Patterns," American Economic Review, LXXXV (1995), 615-623.

Mundell, Robert, "A Theory of Optimum Currency Areas," American Economic Review, LI (1961), 657-665.

Obstfeld, Maurice, and Kenneth Rogoff, "The Six Major Puzzles in International Macroeconomics: Is There a Common Cause?" NBER Macroeconomic Annual (Cambridge, MA: MIT Press, 2000).

Rose, Andrew, "One Money One Market: Estimating the Effect of Common Currencies on Trade," Economic Policy, XXX (2000), 9-48.

Spence, Michael, "Product Selection, Fixed Costs, and Monopolistic Competition," Review of Economic Studies, XXXXIII (1976), 217-235.

Tenreyro, Silvana, "On the Causes and Consequences of Currency Unions," Harvard University, unpublished, 2001. 
Copyright of Quarterly Journal of Economics is the property of MIT Press. The copyright in an individual article may be maintained by the author in certain cases. Content may not be copied or emailed to multiple sites or posted to a listserv without the copyright holder's express written permission. However, users may print, download, or email articles for individual use. 